\title{
亚热带人工林乔灌草根际土壤氮矿化特征
}

\author{
扈明媛 1,2 袁 野 ${ }^{3}$ 戴晓琴 $1,2^{*}$ 付晓莉 1,2 寇 亮 1,2 王辉民 ${ }^{1,2}$ \\ ${ }^{1}$ 中国科学院地理科学与资源研究所生态系统网络观测与模拟重点实验室千烟洲试验站, 北京 $100101 ;{ }^{2}$ 中国科学院大学资源与环境学院, 北京 \\ $100190{ }^{3}$ 安徽师范大学生命科学学院安徽省重要生物资源保护与利用研究重点实验室, 安徽芜湖 241000
}

摘 要 为了探讨人工林内优势乔木和林下灌草根际土壤氮矿化特征, 明确乔灌草根际土壤氮转化差异, 该研究以江西泰和 千烟洲站区典型人工杉木(Cunninghamia lanceolata)、马尾松(Pinus massoniana)和湿地松(Pinus elliottii)林为对象, 在植被生长 季初期(4月)和旺盛期(7月)分析3种人工林内乔木、优势灌木(聯木(Loropetalum chinense)、杨桐(Adinandra millettii)、格药柃 (Eurya muricata))和草本(狗脊蕨(Woodwardia japonica)、暗鳞鳞毛蕨(Dryopteris atrata))根际土壤的净氮矿化速率、土壤化学 性质及土壤微生物特征。结果发现: 1)物种、林型和取样季节显著影响了根际土壤净氮矿化速率 $\left(N_{\min }\right)$ 、净铵化速率 $\left(N_{\mathrm{amm}}\right)$ 和 净硝化速率 $\left(N_{\mathrm{nit}}\right)$ 。马尾松和湿地松林内林下灌草根际土壤净氮矿化的季节敏感性高于乔木: 4 月乔木根际土壤 $N_{\mathrm{min}}$ 和 $N_{\mathrm{amm}}$ 显著 高于大多数林下灌草，而7月林下灌草根际土壤 $N_{\min }$ 和 $N_{\mathrm{amm}}$ 显著提高，与乔木不再具有显著差异，与主成分综合得分方差分析 的结果一致。一般情况下, 杉木林 $N_{\min }$ 和 $N_{\mathrm{nit}}$ 显著高于马尾松林和湿地松林。7月净氮矿化显著高于 4 月。2)土壤铵态氮、硝态 氮、全氮及土壤微生物量氮含量是影响根际土壤净氮矿化的主要因素。土壤化学性质对人工林根际土壤净氮矿化变异的贡献 率为 $29.2 \%$, 显著高于土壤微生物的解释率。充分考虑不同季节林下植被根际土壤的净氮矿化及其关键影响因素可为准确评 估人工林生态系统养分循环状况提供重要支撑。

关键词＼cjkstart根际土壤氮矿化; 林下植被; 乔木; 人工林; 红壤

扈明媛，袁野，戴晓琴，付晓莉，寇亮，王辉民（2020). 亚热带人工林乔灌草根际土壤氮矿化特征．植物生态学报，44，1285-1295. DOI: $10.17521 /$ cjpe.2020.0225

\section{Characteristics of soil nitrogen mineralization in the rhizosphere of trees, shrubs, and herbs in subtropical forest plantations}

\begin{abstract}
HU Ming-Yuan ${ }^{1,2}$, YUAN Ye ${ }^{3}$, DAI Xiao-Qin ${ }^{1,2 *}$, FU Xiao-Li ${ }^{1,2}$, KOU Liang $^{1,2}$, and WANG Hui-Min ${ }^{1,2}$
${ }^{1}$ Qianyanzhou Ecological Research Station, Key Laboratory of Ecosystem Network Observation and Modeling, Institute of Geographic Science and Natural Resources Research, Chinese Academy of Sciences, Beijing 100101, China; ${ }^{2}$ College of Resource and Environment, University of Chinese Academy of Sciences, Beijing 100190, China; and ${ }^{3}$ Anhui Provincial Key Laboratory of the Conservation and Exploitation of Biological Resources, College of Life Science, Anhui Normal University, Wuhu, Anhui 241000, China
\end{abstract}

\section{Abstract}

Aims The objective was to explore the characteristics of soil nitrogen mineralization in the rhizosphere soils of trees, shrubs, and herbs in plantations and their variations among different species, forest types, and seasons.

Methods The rhizosphere soils of trees, shrubs (Loropetalum chinense, Adinandra millettii, and Eurya muricate), and herbs (Woodwardia japonica and Dryopteris atrata) were sampled in the early growth season (April) and the vigorous growth season (July) in Cunninghamia lanceolata, Pinus massoniana, and Pinus elliottii plantations at Qianyanzhou Ecological Research Station, Taihe, Jiangxi. Net mineralization rate $\left(N_{\text {min }}\right)$, net ammonification rate $\left(N_{\mathrm{amm}}\right)$, net nitrification rate $\left(N_{\mathrm{nit}}\right)$, soil chemical properties, and microbial properties were measured.

Important findings The results found that, 1) Species, forest types, and sampling seasons significantly affected $N_{\text {min }}, N_{\text {amm }}$, and $N_{\text {nit }}$. Understory plants showed a higher seasonal sensitivity of rhizosphere soil $N_{\text {nit }}$ than trees did in P. massoniana plantations and P. elliottii plantations. It means that rhizosphere soil $N_{\min }$ and $N_{\text {amm }}$ of trees were significantly higher than those of most of the understory plants in April, but rhizosphere soil $N_{\min }$ and $N_{\text {amm }}$ of the understory plants significantly increased and showed no difference with those of trees in July. This finding was consistent with the variance analysis of comprehensive scores by principal component analysis. Generally, rhizosphere soil $N_{\min }$ and $N_{\text {nit }}$ in C. lanceolata plantation were higher than those in P. massoniana and P. elliottii plantations. Rhizosphere soil nitrogen mineralization in July was higher than those in April. 2) Soil ammonium

收稿日期Received: 2020-07-06 接受日期Accepted: 2020-09-27

基金项目: 国家自然科学基金(41830860和31971634)。Supported by the National Natural Science Foundation of China (41830860 and 31971634 ).

* 通信作者Corresponding author (daixq@igsnrr.ac.cn) 
nitrogen, nitrate nitrogen, soil total nitrogen concentration, and soil microbial nitrogen concentration were the main factors affecting net nitrogen mineralization of rhizosphere soil. Soil chemical properties contributed to $29.2 \%$ of the variation of rhizosphere soil nitrogen mineralization, which was significantly higher than soil microbial properties. Consideration of the seasonal variations of soil nitrogen mineralization in the rhizosphere of understory plants and their influencing factors will provide an important foundation for accurately evaluating nutrient cycling in the plantation ecosystem.

Key words rhizosphere soil nitrogen mineralization; understory vegetation; overstory tree; plantation; red soil

Hu MY, Yuan Y, Dai XQ, Fu XL, Kou L, Wang HM (2020). Characteristics of soil nitrogen mineralization in the rhizosphere of trees, shrubs, and herbs in subtropical forest plantations. Chinese Journal of Plant Ecology, 44, 1285-1295. DOI: 10.17521/cjpe.2020.0225

土壤氮有效性影响着森林生态系统生产力(沙 丽清等, 2000), 而土壤中 $85 \%-95 \%$ 的氮是植物不能 直接利用的有机氮, 需要经过矿化、硝化作用将有 机氮转化为无机氮, 才能被植物吸收利用(李阳等, 2019)。土壤有机氮的矿化主要是微生物驱动的生物 地球化学过程(贺纪正和张丽梅, 2013)。在土壤氮有 效性较低时, 微生物会增加胞外酶的分泌, 通过解 聚合作用将难以利用的有机质分解(Burns et al., 2013)。因此, 土壤微生物(Li et al., 2019)和土壤化学 性质(Liu et al., 2017)共同作用于森林生态系统土壤 氮矿化。

根际是植物与土壤相互作用的热点区域 (Kuzyakov \& Blagodatskaya, 2015)。植物根系的分泌 物和脱落物为森林生态系统土壤微生物活动提供了 大量的碳源和氮源, 提高了根际微生物的生物量和 活性(Phillips et al., 2008), 显著改变了微生物介导 的土壤氮矿化过程。研究发现, 根际活性微生物生 物量是全土的2倍(Blagodatskaya et al., 2014), 根际 水解酶活性比全土提高了3-5倍(Spohn et al., 2013)。 Zhu等(2014)研究表明, 植物活根的存在使土壤中 $\beta$ 葡萄糖苷酶(BG)和氧化酶活性分别增加 $19 \%-56 \%$ 和 $0 \%-46 \%$, 致使土壤总氮矿化速率提高了 $36 \%-62 \%$ 。据估计, 森林生态系统土壤氮矿化的 $1 / 3$ 是由根系分泌物引起的(Finzi et al., 2015)。根际土壤 氮矿化研究对于准确估计整个森林生态系统土壤氮 循环具有非常重要的意义。

已有研究证明, 不同的物种根系形态及生理特 征, 如根系分泌物的质和量(Moreau et al., 2019)、养 分吸收偏好(李常诚等, 2016)、根系周转速率(Gill \& Jackson, 2000)等都具有显著差异, 从而导致其根际 微区土壤微生物群落(Ribbons et al., 2016)、酶活性 (Zhu et al., 2014)、酶化学计量比(高雨秋等, 2019) 等明显不同, 由此造成根际氮矿化的差异。更好地 了解不同物种间根际土壤氮矿化的差异对于精准估
计多物种共存的复杂森林生态系统氮循环过程至关 重要。不同森林生态系统物种层面根际土壤氮矿化 的研究已开展较多(Phillips \& Fahey, 2006; Lin et al., 2018)。如Zhao等(2010)发现樟子松(Pinus sylvestris) 根际土壤净氮矿化和净硝化高于榆树(Ulmus pumlia) 和小叶杨(Populus simonii), 不同树种根际获取养分 的能力不同。Yin等(2012)认为云杉(Picea asperata) 和冷杉(Abies fabri)根际氮转化对气候变暖的响应 模式相似。莫雪莉等(2018)发现灌木聯木(Loropetalum chinense)有效氮及其他养分的根际效应强于 杨桐(Adinandra millettii)和格药柃(Eurya muricata)。 然而, 目前研究多集中在不同森林生态系统优势乔 木或灌木物种, 关于同一森林生态系统内共生的乔 木、灌木和草本之间根际土壤氮矿化的比较研究相 对缺乏。林下植被是森林生态系统的重要组成部分, 对于森林生态系统结构和功能维持及其稳定性的提 高具有不容忽视的作用(马姜明和李昆, 2004)。林下 植被生物量周转速率远远高于乔木, 特别是在人工 针叶林中, 促进了生态系统的养分吸收(Nilsson \& Wardle, 2005)。研究发现, 亚热带表层土壤(0-20 cm) 中林下植物的根系总细根生物量、吸收根的分枝比 均高于乔木(Jiang et al., 2018), 如杉木(Cunninghamia lanceolata)林林下植被细根生物量占林地内细根总 产量的 $16.7 \%-29.4 \%$ (Fu et al., 2015a)。林下植被的 去除减少了根系分泌物和细根周转, 使土壤中有机 质和微生物量降低, 进而减少了潜在净氮矿化 (Wang et al., 2014)。因此林下植被根际土壤氮矿化 对于整个森林生态系统养分循环的影响不容忽视。

杉木、马尾松 (Pinus massoniana) 和湿地松 (Pinus elliottii)人工纯林是我国中亚热带地区主要 人工林类型(Dai et al., 2018), 林下物种丰富。我们 前期研究发现, 不同林下植被土壤养分的根际效 应、土壤酶活性均具有差异，且对不同林分类型响 应不同(莫雪丽等, 2018; 高雨秋等, 2019), 必然引

www.plant-ecology.com 
起根际土壤氮矿化的差异。本研究以中亚热带典型 人工杉木、马尾松和湿地松林为研究对象, 分析乔 木、灌木和草本在不同林分类型及取样季节根际土 土壤净氮矿化速率、土壤化学性质及土壤微生物特 征, 探讨人工林内乔灌草根际土壤的净氮矿化特征 及其驱动因素, 为准确评估中亚热带红壤丘陵区人 工林生态系统养分循环提供重要理论依据。

\section{1 材料和方法}

\section{1 研究区概况}

试验地设在中国科学院千烟洲亚热带森林生态 系统观测研究站(原中国科学院-江西省千烟洲红壤 丘陵综合开发试验站, 简称千烟洲站), 位于江西省 吉安市泰和县灌溪镇 $\left(115.07^{\circ} \mathrm{E}, 26.75^{\circ} \mathrm{N}\right)$, 海拔 $100 \mathrm{~m}$ 左右, 相对高差20-50 m。站区属于亚热带季 风气候区, 年平均气温 $17.9{ }^{\circ} \mathrm{C}$, 年降水量为 $1489 \mathrm{~mm}$ 。主要土壤类型为红壤, 成土母质多为红 色砂岩、砂砾岩。站区植被覆盖原为亚热带常绿阔 叶林, 于 20 世纪 80 年代破坏殆尽。本研究中典型人 工林包括人工杉木林、马尾松林和湿地松林, 于 1985 年前后营造, 林龄 32 年左右, 密度分别为 $2440 、 1960$ 和 2060 株 $\cdot \mathrm{hm}^{-2}$, 郁闭度分别为 0.77 、 0.79 和 0.75 , 平均树高和平均胸径分别为 $17.2 、 20.2$ 、 $22.0 \mathrm{~m}$ 和20.5、19.6、24.6 cm。林下灌木主要有柪木、 杨桐和格药柃, 平均基径分别为 $2.07 、 2.23$ 和 $1.70 \mathrm{~cm}$, 重要值分别为 $30.6 \% 、 27.0 \%$ 和 $19.7 \%$ 。林下草本主 要有狗脊偋 (Woodwardia japonica)、暗鳞鳞毛蕨 (Dryopteris atrata), 盖度分别为 $68.0 \%$ 和 $44.7 \%$, 重 要值分别为 $3.7 \%$ 和 $2.5 \%$ (莫雪丽等, 2018 ; 高雨秋 等, 2019)。

\section{2 土壤样品采集}

采样时间为 2017 年 4 月中旬, 采用随机区组实 验设计。以千烟洲试验站 5 个独立的山头作为 5 个区 组, 各区组内随机选择杉木、马尾松和湿地松 3 种人 工林, 分别设置 1 个 $20 \mathrm{~m} \times 20 \mathrm{~m}$ 的标准样方。每个样 方内分别采集优势乔木(杉木、马尾松和湿地松)、灌 木(檵木、杨桐和格药柃)和草本(狗脊偋和暗鳞鳞毛 蒝)的根际土样。同年7月中旬重复采样一次。研究前 期发现, 造林前 3 种林分类型以及重复区组之间的本 底环境具有一致性(Fu et al., 2015b; Dai et al., 2018)。

根际土样选择0-20 cm土壤进行采集。根际土取 样采用根系追踪法, 于不同方位多点采样混合。每
块样地随机选择3-5株植株, 收集直径 $5 \mathrm{~mm}$ 以下根 系的根际土壤, 即轻轻抖落后仍黏附根系表面 $4 \mathrm{~mm}$ 以内的土壤(Phillips et al., 2008)。采用S形布点 法进行全土的混合取样。采取土样后去除石砾、植 物根等杂物, 过 $2 \mathrm{~mm}$ 篮后一部分立即储存在 $4{ }^{\circ} \mathrm{C}$ 冰箱, 另一部分风干, 便于后续分析。

\section{3 土壤样品分析}

\subsection{1 净氮矿化、净铵化和净硝化速率测定}

称50 g鲜土置于 $500 \mathrm{~mL}$ 塑料瓶中, 瓶盖上打若 干小孔透气，土壤含水量调节到 $60 \%$ 饱和含水量后， 放入 $25{ }^{\circ} \mathrm{C}$ 培养箱内培养 28 天。培养过程中每隔2-3 天称质量进行调节，使土壤含水量维持在 $60 \%$ 饱和 含水量。分别于培养前和培养结束后测定土壤 $\mathrm{NO}_{3}^{-}-\mathrm{N}$ 和 $\mathrm{NH}_{4}^{+}-\mathrm{N}$ 含量。根据培养前后 $\mathrm{NO}_{3}^{-}-\mathrm{N}$ 和 $\mathrm{NH}_{4}^{+}-\mathrm{N}$ 含量的差值计算净氮矿化速率 $\left(N_{\min }\right)$ 、净铵化 速率 $\left(N_{\mathrm{amm}}\right)$ 和净硝化速率 $\left(N_{\mathrm{nit}}\right)$ 。计算公式如下(单位 为 $\mathrm{mg} \mathrm{N} \cdot \mathrm{kg}^{-1} \cdot \mathrm{d}^{-1}$, 即单位时间内无机氮含量的变化): $N_{\min }=$ (培养后 $\mathrm{NO}_{3}^{-}-\mathrm{N}$ 和 $\mathrm{NH}_{4}^{+}-\mathrm{N}$ 含量之和-培养 前 $\mathrm{NO}_{3}^{-}-\mathrm{N}$ 和 $\mathrm{NH}_{4}^{+}-\mathrm{N}$ 含量之和 $)$ 培养天数

$N_{\mathrm{amm}}=$ (培养后 $\mathrm{NH}_{4}^{+}-\mathrm{N}$ 含量-培养前 $\mathrm{NH}_{4}^{+}-\mathrm{N}$ 含 量)/培养天数

$N_{\text {nit }}=\left(\right.$ 培养后 $\mathrm{NO}_{3}^{-}-\mathrm{N}$ 含量-培养前 $\mathrm{NO}_{3}^{-}-\mathrm{N}$ 含量 $)$ 培养天数

\subsection{2 土壤微生物生物量碳、氮含量测定}

土壤微生物生物量采用氯仿熏蒸 $-\mathrm{K}_{2} \mathrm{SO}_{4}$ 提取法 (Vance et al., 1987)获取。取 $25 \mathrm{~g}$ 鲜土置于 $100 \mathrm{~mL}$ 塑 料瓶中, 放入真空干燥器内, 干燥器内另内置 $100 \mathrm{~mL}$ 无醇氯仿、 $100 \mathrm{~mL} \mathrm{NaOH}$ 溶液和 $100 \mathrm{~mL} \mathrm{H}_{2} \mathrm{O}$, 抽真空至氯仿呈沸腾状态, 保持 $5 \mathrm{~min}$, 之后保持真 空, 将干燥器移至黑暗条件下 $24 \mathrm{~h} 。 24 \mathrm{~h}$ 后将盛有氯 仿的烧杯取出, 反复抽真空至土壤中氯仿完全去 除。在塑料瓶内加入 $100 \mathrm{~mL} 0.5 \mathrm{~mol} \cdot \mathrm{L}^{-1} \mathrm{~K}_{2} \mathrm{SO}_{4}$ (土水 质量比为 $1: 4)$, 振荡 $30 \mathrm{~min}$ 后过滤。滤液中的碳用总 有机碳分析仪(Liquid TOCII, Elementar, Frankfurt, Germany)测定，氮用流动分析仪(AA3, Bran Luebbe, Hamburg, Germany)测定。同时另取未氯仿熏蒸的土 壤按上述方法培养、提取和测定, 微生物生物量碳 $(\mathrm{MBC})$ 含量为熏蒸前后所测碳之差除以转换系数 0.45 , 微生物生物量氮( $(M B N)$ 含量为熏蒸前后所测 氮含量之差除以转换系数 0.54 。

\subsection{3 土壤酶活性测定}

土壤酶活性测定采用微孔板苂光法(Bell et al., 
2015)。反应底物浓度为 $200 \mu \mathrm{mol} \cdot \mathrm{L}^{-1}$ 。具体方法为: 称 $1 \mathrm{~g}$ 鲜土, 加入 $125 \mathrm{~mL}$ 醋酸缓冲液 $\left(50 \mathrm{mmol} \cdot \mathrm{L}^{-1}\right.$, $\mathrm{pH}$ 5.0), 用旋浴振荡器混匀制成土壤悬浮液。在微 孔板内加入 $200 \mu \mathrm{L}$ 土壤悬浮液和 $50 \mu \mathrm{L}$ 底物, 在 $20{ }^{\circ} \mathrm{C}$ 的黑暗条件下培养 $4 \mathrm{~h}$, 加入 $10 \mu \mathrm{L} \mathrm{NaOH}$ 溶液 $\left(1 \mathrm{~mol} \cdot \mathrm{L}^{-1}\right)$ 终止反应, 之后用多功能酶标仪(Synergy $\mathrm{H} 4$, BioTek, Winooski, USA) 在 $365 \mathrm{~nm}$ 波长激发, $450 \mathrm{~nm}$ 波长荧光测定。

\subsection{4 土壤化学性质测定}

$\mathrm{NH}_{4}^{+}-\mathrm{N} 、 \mathrm{NO}_{3}^{-}-\mathrm{N}$ 采用 $1 \mathrm{~mol} \cdot \mathrm{L}^{-1} \mathrm{KCl}$ 溶液浸提 $(土$ 液质量比为 $1: 5)$, 有效磷( $\mathrm{AP})$ 采用 $\mathrm{NH}_{4} \mathrm{~F}\left(0.03 \mathrm{~mol} \cdot \mathrm{L}^{-1}\right)$ 和 $\mathrm{HCl}\left(0.025 \mathrm{~mol} \cdot \mathrm{L}^{-1}\right)$ 浸提 $($ 土液质量比为 $1: 10)$, 总 磷(TP) 采用酸溶, 之后分别用流动分析仪 (AA3, Bran Luebbe, Hamburg, Germany)测定; 溶解有机碳 (DOC) 用超纯水浸提 (土水质量比为 $1: 5$ ), 总有机碳 分析仪(Liquid TOCII, Elementar, Frankfurt, Germany) 测定; 总碳(TC) 和总氮(TN) 含量采用元素分析仪 (Vario Max CN, Elementar, Frankfurt, Germany)测定; 土壤 $\mathrm{pH}$ 采用 $\mathrm{pH}$ 计法 (土水质量比为 $1: 2.5$ ) 测定。 $\mathrm{C}: \mathrm{N}$ 为总碳和总氮含量的比值, $C: P 、 N: P$ 同理。

\section{4 数据分析}

胞外酶的生态化学计量比可以反映微生物代谢 和营养需求及环境中有效养分之间的生化平衡, 是 衡量土壤微生物能量和养分资源限制状况的重要指 标(Sinsabaugh \& Follstad Shah, 2012; 高雨秋等, 2019), 近年来已被广泛作为微生物特征的重要指 标之一(Chen et al., 2019)。因此, 酶化学计量作为微 生物特征指标用于分析其对土壤氮矿化的影响。酶 $\mathrm{C}: \mathrm{N}$ 通过 $(\alpha-1,4-$ 葡萄糖苷酶 $(\mathrm{AG})+\beta-1,4$-葡萄糖苷 酶 $(\mathrm{BG})+\beta-1,4-$ 木糖苷酶 $(\mathrm{BX})+$ 纤维素二糖水解酶 $(\mathrm{CBH})):(\beta-1,4-\mathrm{N}-$ 乙酰葡糖氨糖苷酶 $(\mathrm{NAG})+$ 亮氨酸 氨基肽酶(LAP))计算, 酶 $\mathrm{C}: \mathrm{P}$ 通过 $(\mathrm{AG}+\mathrm{BG}+\mathrm{BX}+$ $\mathrm{CBH})$ :酸性磷酸酶( $\mathrm{PHOS})$ 计算, 酶 $\mathrm{N}: \mathrm{P}$ 通过 $(\mathrm{NAG}+$ LAP):PHOS计算。

物种类型、林分类型和取样季节对净氮矿化速 率、净铵化速率、净硝化速率的影响以及对土壤化 学性质和土壤微生物性质的影响, 采用混合线性模 型分析。对净氮矿化速率、净铵化速率、净硝化速 率进行主成分分析(PCA), 然后对各物种的综合得 分进行单因素方差分析以比较物种间差异。土壤化 学性质和土壤微生物性质与净氮矿化速率、净铵化
速率、净硝化速率之间的关系采用圥余分析(RDA)。 首先对土壤化学性质 $\left(\mathrm{pH} 、 \mathrm{NO}_{3}^{-}-\mathrm{N} 、 \mathrm{NH}_{4}^{+}-\mathrm{N} 、 \mathrm{DOC} 、\right.$ $\mathrm{TC} 、 \mathrm{TN} 、 \mathrm{TP} 、 \mathrm{C}: \mathrm{N} 、 \mathrm{C}: \mathrm{P} 、 \mathrm{~N}: \mathrm{P} 、 \mathrm{AP}$ 含量) 和土壤微 生物 $(\mathrm{C}$ 相关酶活性 $(\mathrm{AG}+\mathrm{BG}+\mathrm{BX}+\mathrm{CBH}) 、 \mathrm{~N}$ 相关 酶活性(NAG + LAP)、P相关酶活性(PHOS)、酶C:N、 酶 $\mathrm{C}: \mathrm{P} 、$ 酶 $\mathrm{N}: \mathrm{P} 、 \mathrm{MBN} 、 \mathrm{MBC}$ 含量)两部分共 19 个变 量进行方差膨胀因子分析(VIF), 判断解释变量间 的共线性关系, 剔除共线性严重的变量。之后进行 前向选择和显著性检验, 最终确定对净氮矿化速 率、净铵化速率、净硝化速率有显著影响的因素(共 4 个: $\mathrm{NH}_{4}^{+}-\mathrm{N} 、 \mathrm{NO}_{3}^{-}-\mathrm{N} 、 \mathrm{TN} 、 \mathrm{MBN}$ 含量, 结果和讨论 部分将基于此详细展开)。综合所有林分下的数据, 对物种根际土壤 $\mathrm{NH}_{4}^{+}-\mathrm{N}$ 和 $\mathrm{TN}$ 含量进行多重比较。方 差分解分析(VPA)被用于评价土壤化学性质与土壤 微生物在根际土壤氮矿化变异中的相对重要性。

运用SPSS 23.0和R语言进行统计分析, SigmaPlot 12.5作图。PCA、RDA、VIF及VPA基于R语言 中的vegan程序包(Borcard et al., 2011)完成。

\section{2 结果和分析}

\section{1 乔灌草的根际土壤氮矿化}

物种类型显著影响了根际土壤净氮矿化速率、 净铵化速率和净硝化速率 $(p<0.001$, 图1)。如在 4 月 的马尾松林和湿地松林内, 乔木根际土壤 $N_{\min }$ 和

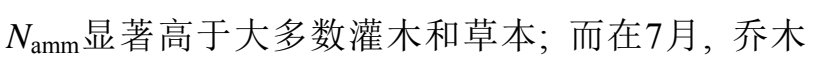
与林下灌木之间差异不显著, 仅马尾松林内狗脊蒝 根际土壤 $N_{\text {nit }}$ 显著高于杨桐和格药柃, 湿地松林内 暗鳞鳞毛蕨根际土壤 $N_{\text {nit }}$ 显著高于湿地松、聯木和格 药柃(图1)。PCA综合得分的方差分析表明, 马尾松 和湿地松根际土壤氮矿化在4月明显区别于其他物 种(杉木和林下灌草)(图2, $p=0.001$ ); 而在7月乔灌 草各物种之间没有显著差异 $(p=0.420)$ 。

林分类型显著影响了根际土壤净氮矿化速率和 净硝化速率 $(p<0.001$, 图1), 基本表现为杉木林显 著高于马尾松林和湿地松林, 主要体现在7月。取样 季节显著影响了根际土壤净氮矿化速率、净铵化速 率和净硝化速率 $(p<0.001)$, 具体表现为7月显著高 于4月, 这种差异主要体现在杨桐、格药柃、狗脊䓲 和暗鳞鳞毛葓(图1)。

\section{2 根际土壤氮矿化的笛余分析和变差分解}

RDA结果表明 19 个土壤化学性质及土壤微生 


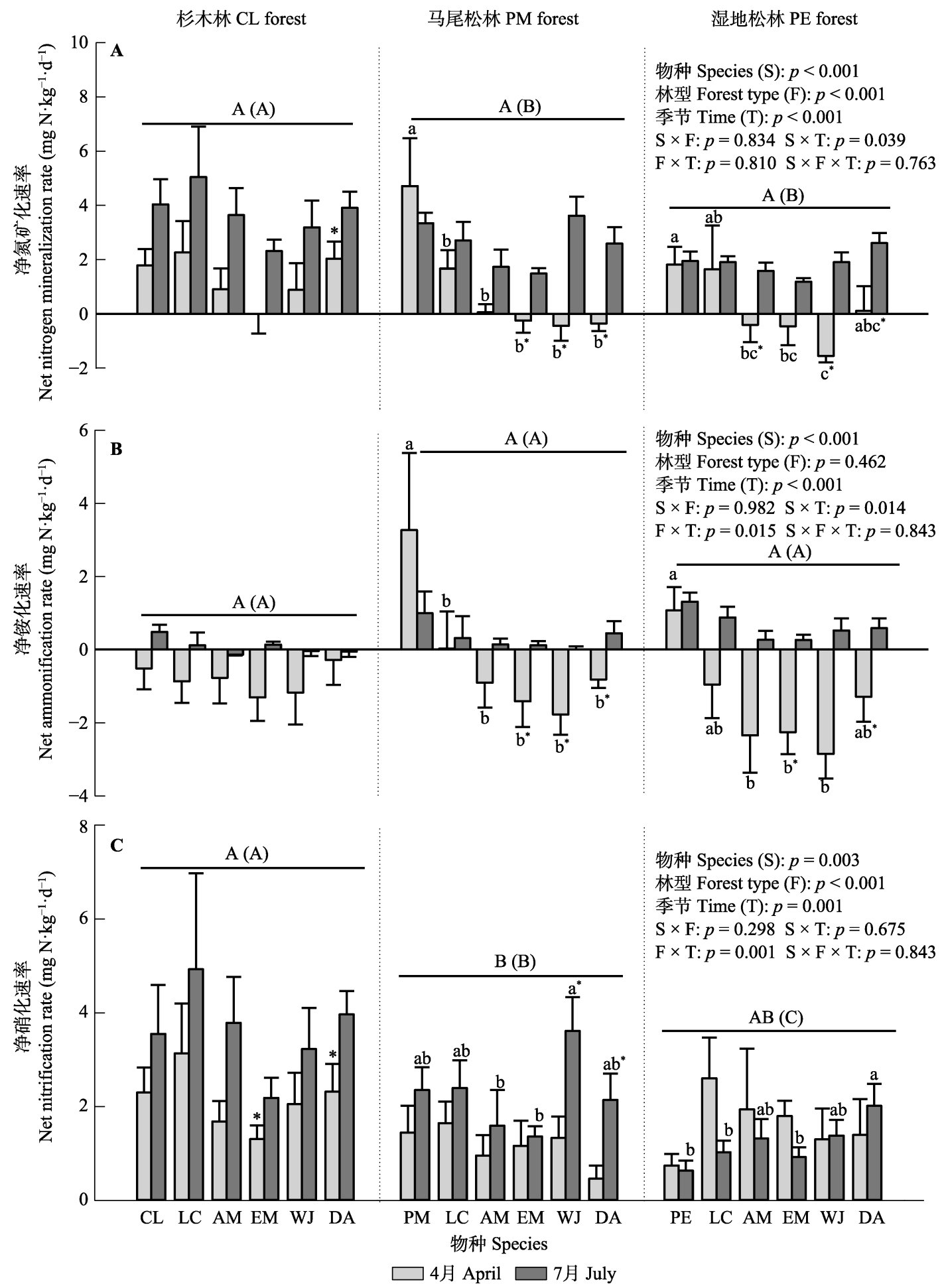

图1 亚热带人工林内乔灌草根际土壤净氮矿化速率 $(\mathbf{A}) 、$ 净铵化速率 $(\mathbf{B})$ 和净硝化速率 $(\mathbf{C})$ 。 AM, 杨桐; CL, 杉木; DA，暗鳞

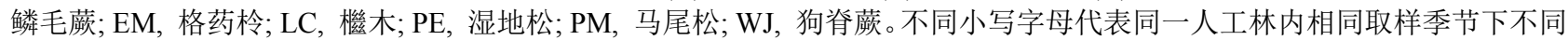
物种之间差异显著 $(p<0.05)$, 未标注小写字母则表示差异不显著。不同大写字母代表相同取样季节不同人工林类型间差异显 著(括号内为4月，括号外为7月; $p<0.05)$ 。代表同一人工林内相同物种不同取样季节差异显著 $(p<0.05)$ 。

Fig. 1 Net mineralization rate $\left(N_{\min }\right)$, net ammonification rate $\left(N_{\mathrm{amm}}\right)$, and net nitrification rate $\left(N_{\text {nit }}\right)$ of the rhizosphere soil of overstory trees, understory shrubs, and herbs in subtropical plantations. AM, Adinandra millettii; CL, Cunninghamia lanceolata; DA, Dryopteris atrata; EM, Eurya muricate; LC, Loropetalum chinense; PE, Pinus elliottii; PM, Pinus massoniana; WJ, Woodwardia japonica. Different lowercase letters denote significant difference among species of each plantation in the same season $(p<0.05)$, while unmarked lowercase letters denote inapparent difference. Different uppercase letters denote significant difference among plantations in the same season (April is in the bracket, July is outside the bracket; $p<0.05$ ). *denotes significant difference between the different seasons for the same species in each plantation $(p<0.05)$. 

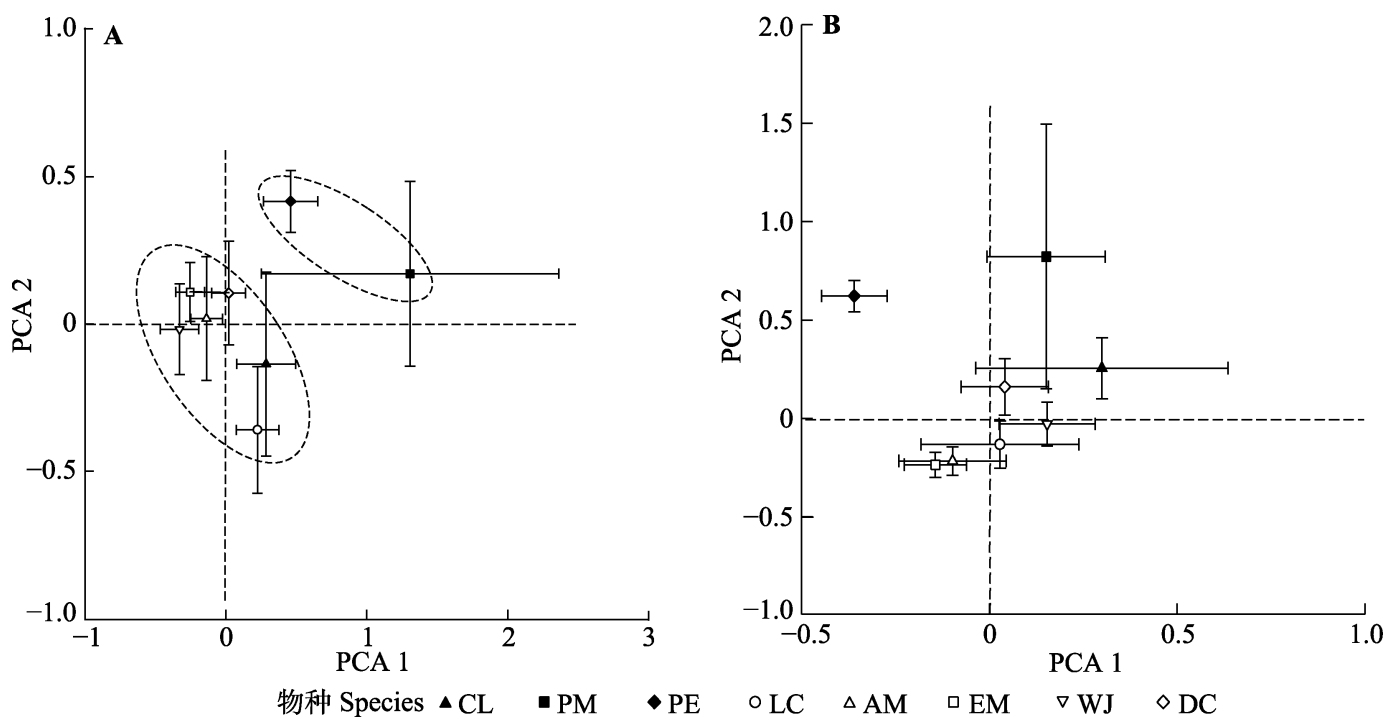

图2 亚热带人工林内乔灌草根际土壤净氮矿化速率、净铵化速率和净硝化速率的主成分分析(PCA)。A, 4月。B, 7月。AM, 杨 桐; CL，杉木; DA，暗鳞鳞毛蕨; EM，格药柃; LC，聯木; PE，湿地松; PM，马尾松; WJ，狗脊硕。

Fig. 2 Principal component analysis (PCA) of net nitrogen mineralization rate, net ammonification rate, and net nitrification rate of the rhizosphere soil of trees, understory shrubs, and herbs within subtropical plantations. A, April. B, July. AM, Adinandra millettii; CL, Cunninghamia lanceolata; DA, Dryopteris atrata; EM, Eurya muricate; LC, Loropetalum chinense; PE, Pinus elliottii; PM, Pinus massoniana; WJ, Woodwardia japonica.

物特征因子共解释了根际土壤氮矿化变异的 $50.6 \%$ 。 剔除共线性变量、前向选择和显著性检验后剩余 $\mathrm{NH}_{4}^{+}-\mathrm{N} 、 \mathrm{NO}_{3}^{-}-\mathrm{N} 、 \mathrm{TN}$ 及BN含量4个因素极显著影 响了根际土壤氮矿化，仍能够解释变异的 $43.3 \%$ (图 3)。土壤化学性质对根际土壤氮矿化变异的贡献率 为 $29.2 \%$, 土壤微生物的贡献率为 $6.5 \%$ (图4)。

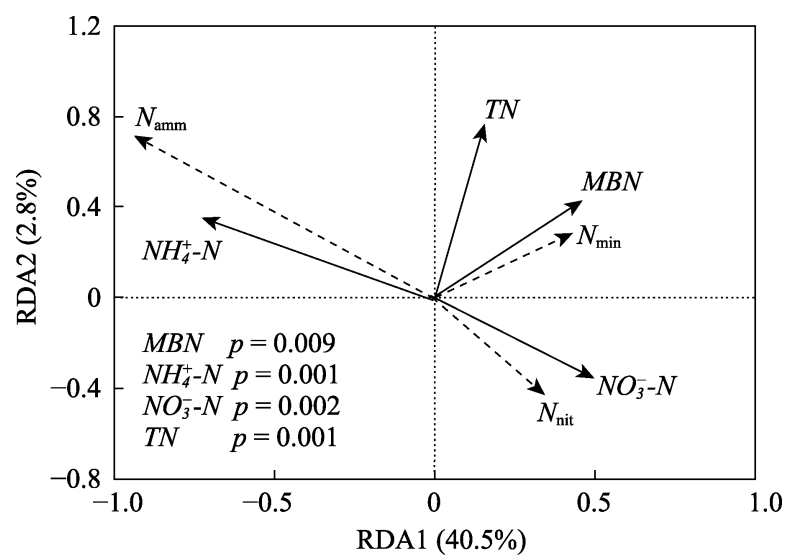

图3 亚热带人工林根际土壤净氮矿化速率 $\left(N_{\min }\right)$ 、净铵化速 率 $\left(N_{\mathrm{amm}}\right)$ 和净硝化速率 $\left(N_{\mathrm{nit}}\right)$ 与土壤化学性质和土壤微生物 关系的㝋余分析(RDA)。 $M B N$, 微生物量氮含量; $N H_{4}^{+}-N$, 铵 态氮含量; $N_{3}^{-}-N$, 硝态氮含量; $T N$, 全氮含量。

Fig. 3 Redundancy analysis (RDA) of the relationship between net nitrogen mineralization rate $\left(N_{\min }\right)$, net ammonification rate $\left(N_{\mathrm{amm}}\right)$, and net nitrification rate $\left(N_{\text {nit }}\right)$ of the rhizosphere soil and soil chemical properties and soil microbial properties in subtropical plantations. $M B N$, microbial biomass nitrogen concentration; $\mathrm{NH}_{4}^{+}-\mathrm{N}$, ammonium nitrogen concentration; $\mathrm{NO}_{3}^{-}-\mathrm{N}$, nitrate nitrogen concentration; $\mathrm{TN}$, soil total $\mathrm{N}$ concentration.

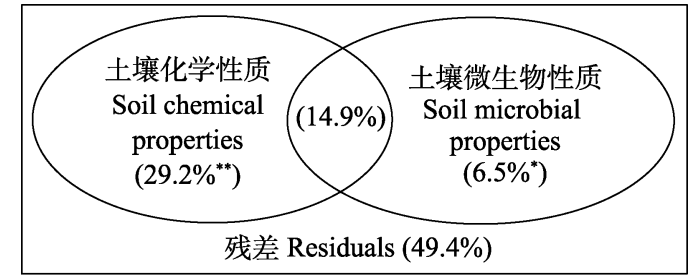

图4 亚热带人工林土壤化学和微生物性质在根际土壤净氮 矿化速率、净铵化和净硝化速率变异中的相对贡献。每个椭 圆表示由土壤化学性质或土壤微生物性质能解释的变异百 分比。椭圆重叠部分表示土壤化学性质和土壤微生物性质共 同解释的比例。*表示影响显著 $(p<0.05)$, **表示影响极显著 $(p<0.01)$ 。

Fig. 4 Relative importance of soil chemical and soil microbial properties in determining the variation in net nitrogen mineralization rate, net ammonification rate, and net nitrification rate of the rhizosphere soil in subtropical forest plantations. Each ellipse represents the percentage of the variations explained by soil chemical properties or soil microbial properties. The overlap of two ellipses represents the variation jointly explained by soil chemical and microbial properties. *indicates a significant effect $(p<0.05), * *$ indicates a highly significant effect $(p<$ $0.01)$

\section{3 讨论}

\section{1 根际土壤氮矿化特征}

全球土壤净氮矿化的平均值为 $2.41 \mathrm{mg} \cdot \mathrm{kg}^{-1} \cdot \mathrm{d}^{-1}$, 其中森林生态系统平均为 $2.16 \mathrm{mg} \cdot \mathrm{kg}^{-1} \cdot \mathrm{d}^{-1}$ (Liu et al., 2016, 2017)。由于红壤养分贫㾑, 矿化作用微弱(李 辉信等, 2000), 虽然根系分泌物和脱落物可以为微 生物提供充足的碳源和氮源，提高微生物活性，并 
且根际分泌物中部分物质还可以吸引和促进固氮菌, 进而提高根际土壤氮矿化(吴林坤等, 2014), 但与全 球和森林生态系统来比, 本研究中根际土壤净氮矿 化并没有太大提高。这主要是因为研究区域处亚热 带季风气候, 高温多雨, 矿物风化和水土流失严重, 加之酸雨的影响和 20 世纪 80 年代长期不合理的开发 利用, 导致红壤养分贫㾑化及红壤退化, 氮矿化较 弱(赵其国, 1995)。

本研究中根际土壤净氮矿化速率以净硝化速率 为主, 净铵化速率较小甚至为负值, 与以往大量的 研究结果(沙丽清等, 2000; 王光军等, 2009; Urakawa et al., 2016)一致。研究发现不同森林生态系统 之间净硝化占净氮矿化的比例差异很大, 变化范围 为0-80\% (Gilliam et al., 2001)。硝化作用在不同的 森林生态系统中具有很大的不确定性。一方面, 亚 热带和热带森林土壤通常具有快速的氮循环速率, 相对温带森林生态系统, 湿润的亚热带和热带森林 可以实现氮富集(Zhang et al., 2013a), 导致硝酸盐 主导的氮循环过程变强, 硝化作用也有可能较强 (Aber et al., 1989)。另一方面, 亚热带酸性土壤微生 物的自养硝化速率虽然较低, 但异养硝化速率较高, 可以将有机氮直接转化为硝态氮, 并且部分进行硝 化作用的微生物对酸性红壤低 $\mathrm{pH}$ 的环境有很好的 适应性(Zhang et al., 2011, 2013b)。另外, 较强的微 生物固持导致铵化作用产生的铵态氮迅速被微生物 固定(陈伏生等, 2004), 使得净铵化速率较小甚至为 负值。

\section{2 物种对根际土壤氮矿化的影响}

York等(2016)认为根际最简明的定义是受植物 根系影响的土壤, 其区域在几厘米的范围之内。不 同的物种其根系形态及生理特性不同 (Fu et al., 2015a; 莫雪丽等, 2018), 导致其根际土壤氮矿化存 在差异。本研究发现马尾松和湿地松林内, 4月乔木 根际土壤 $N_{\mathrm{min}}$ 和 $N_{\mathrm{amm}}$ 显著高于大多数林下灌草, 而7

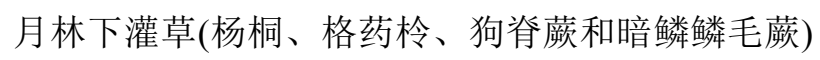
根际土壤 $N_{\min }$ 和 $N_{\mathrm{amm}}$ 显著提升, 与乔木不再具有显 著差异(图1)。这体现出乔木与林下灌草根际土壤氮 矿化季节敏感性的差异, 具体表现为杨桐、格药柃、 狗脊蕨和暗鳞鳞毛硕根际土壤氮矿化季节敏感性强 于马尾松和湿地松, 与杉木则没有差异。一方面, 不 同的物种对铵态氮、硝态氮及小分子有机氮的吸收
偏好具有差异(Moreau et al., 2019), 使得物种之间 根际土壤 $\mathrm{NH}_{4}^{+}-\mathrm{N}$ 含量具有显著差异(表1), 显著影响 根际土壤氮矿化(图3)。如李常诚等(2016)发现相对 于硝态氮和甘氨酸, 杉木偏好吸收铵态氮。另一方 面, 根际土壤 TN含量也对其氮矿化具有显著影响 (图3), 反映了基质有效性在调节无机氮生产中的重 要性(Booth et al., 2005)。其他研究也表明, 土壤 $\mathrm{NH}_{4}^{+}-\mathrm{N}$ 和 $\mathrm{TN}$ 含量对土壤净氮矿化具有显著影响(肖 好燕等, 2017; Zulkarnaen et al., 2019)。本研究发现, 马尾松、湿地松和聯木的 $\mathrm{NH}_{4}^{+}-\mathrm{N}$ 和 $\mathrm{TN}$ 含量显著高于 杉木、杨桐、格药柃、狗脊硕和暗鳞鳞毛蕨(表1; 图 5), 这可能与这些物种的菌根类型有一定的关系。 研究证明外生菌根和从枝菌根树种对土壤氮循环的 影响存在差异(Phillips et al., 2013), 其中外生菌根 树种具有更封闭的氮循环, 氮周转慢(Lin et al., 2018), 由此造成了根际土壤氮矿化相对较低的季 节敏感性。本研究中马尾松、湿地松和綝木为外生 菌根物种, 杉木、杨桐、格药柃、狗脊蒝和暗鳞鳞 毛偋为丛枝菌根或无从枝菌根物种(苏琍英等, 1992; 高雨秋等, 2019)。此外, 研究发现细根直径越大, 其 对环境因子的响应就越不敏感(Hodge, 2004)。乔木 较灌木来说细根直径较粗(王新洲等, 2010), 导致乔 木对环境的敏感度不及灌木和草本。

\section{3 林分类型对根际土壤氮矿化的影响}

林分类型决定了调落物层的特征, 影响了土壤 化学和微生物性质, 进而影响了氮转化速率(Booth et al., 2005; Urakawa et al., 2016)。肖好燕等(2017) 对亚热带天然林、格氏栲(Castanopsis kawakamii)人

表1 物种、林型和季节对亚热带人工林 4 个主要土壤化学和微生物性质 影响的混合线性模型分析结果( $p$ 值)

Table 1 Mixed linear model analysis of the effects of species, forest types, and seasons on four main soil chemical and microbial properties in subtropical forest plantations ( $p$ value)

\begin{tabular}{lcccc}
\hline 变异来源 Source of variation & $\mathrm{NH}_{4}^{+}-\mathrm{N}$ & $\mathrm{NO}_{3}^{-}-\mathrm{N}$ & $T N$ & $M B N$ \\
\hline 物种 Specise (S) & $<0.001^{* *}$ & 0.082 & $<0.001^{* *}$ & 0.136 \\
林型 Forest type (F) & $0.002^{* *}$ & $<0.000^{* *}$ & 0.303 & 0.695 \\
季节 Time (T) & $<0.001^{* *}$ & $<0.001^{* *}$ & 0.725 & $0.002^{* *}$ \\
$\mathrm{~S} \times \mathrm{F}$ & 0.773 & 0.590 & 0.769 & 0.901 \\
$\mathrm{~S} \times \mathrm{T}$ & 0.928 & 0.626 & 0.929 & 0.931 \\
$\mathrm{~F} \times \mathrm{T}$ & 0.026 & 0.061 & 0.516 & 0.086 \\
$\mathrm{~S} \times \mathrm{F} \times \mathrm{T}$ & 0.581 & 0.854 & 0.655 & 0.727 \\
\hline
\end{tabular}

$M B N$, 微生物生物量氮含量; $T N$, 土壤全氮含量. $* *, p<0.01$. $M B N$, microbial biomass nitrogen concentration; $T N$, soil total N concentration. ${ }^{* *}, p<0.01$. 

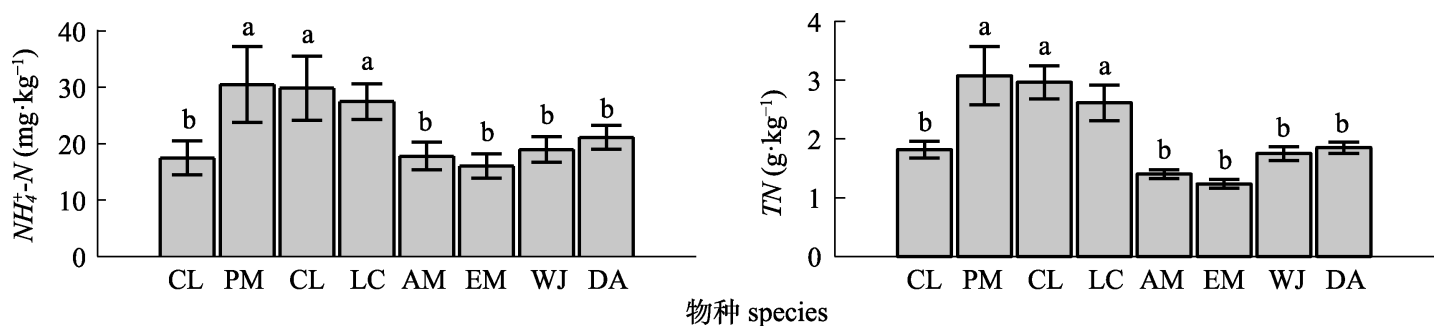

图5 亚热带人工林不同物种根际土壤铵态氮 $\left(N H_{4}^{+}-N\right)$ 和全氮含量 $(T N)$ 的多重比较(平均值土标准误差)。AM, 杨桐; CL, 杉木; DA, 暗鳞鳞毛茨; EM, 格药柃; LC, 聯木; PE, 湿地松; PM，马尾松; WJ, 狗脊屏。不同小写字母表明物种之间差异显著 $(p<$ 0.05)。

Fig. 5 Multiple comparison of soil ammonium nitrogen $\left(\mathrm{NH}_{4}^{+}-\mathrm{N}\right)$ and total soil nitrogen concentrations $(\mathrm{TN})$ in the rhizosphere soil of different species in subtropical forest plantations (mean $\pm S E$ ). AM, Adinandra millettii; CL, Cunninghamia lanceolata; DA, Dryopteris atrata; EM, Eurya muricate; LC, Loropetalum chinense; PE, Pinus elliottii; PM, Pinus massoniana; WJ, Woodwardia japonica. Different lowercase letters showed significant differences among species $(p<0.05)$.

工林和杉木人工林的研究发现，林分类型显著影响 土壤净氮矿化速率、净硝化速率及净铵化速率。本 研究发现杉木林根际土壤 $N_{\text {min }}$ 和 $N_{\text {nit }}$ 显著高于马尾 松和湿地松林(图1), 可能与 $\mathrm{NH}_{4}^{+}-\mathrm{N}$ 对根际土壤氮矿 化和硝化的抑制作用有关(图3)。本研究中杉木林根 际土壤 $\mathrm{NH}_{4}^{+}-\mathrm{N}$ 含量显著低于马尾松林和湿地松林 $(p<0.05)$ 。根系环境中高浓度的 $\mathrm{NH}_{4}^{+}-\mathrm{N}$ 会引发根系 生物硝化抑制剂的释放, 对氨氧化细菌和氨氧化古 菌都产生抑制作用(Subbarao et al., 2007)。在取样和 室内培养之前, 马尾松和湿地松林中较高浓度的 $\mathrm{NH}_{4}^{+}-\mathrm{N}$ 使硝化抑制剂在根际土壤形成积累, 导致培 养时与硝化作用有关的微生物数量及活性的降低, 进而影响了 $N_{\min }$ 和 $N_{\text {nit }}$ 。另一方面, 可能因为杉木是 从枝菌根(AM)树种, 马尾松和湿地松是外生菌根 $(\mathrm{ECM})$ 树种。ECM真菌可以产生胞外酶, 直接从土 壤有机质中获得有机氮, 而 $\mathrm{AM}$ 真菌缺乏胞外酶的 分泌能力(Talbot et al., 2008), 这种差异造成ECM真 菌和腐生生物强烈的氮竞争, 从而降低了土壤有机 质分解速率(Lin et al., 2018), 使得 $\mathrm{AM}$ 森林土壤 $N_{\text {min }}$ 和 $N_{\text {nit }}$ 显著高于ECM森林(Phillips et al., 2013)。同时, $\mathrm{ECM}$ 树种调落物质量低于 $\mathrm{AM}$ 树种, 使得ECM树下 土壤净氮矿化速率和净硝化速率显著低于 $\mathrm{AM}$ 树 (Lin et al., 2018)。

\section{4 取样季节对根际土壤氮矿化的影响}

在温度、降水、植物等多种因子的共同调控下， 土壤氮循环形成了特殊的季节模式(Parker \& Schimel, 2011)。本研究表明, 取样季节显著影响了 $N_{\min }$ 、 $N_{\text {amm }}$ 和 $N_{\text {nit }}$ (图1), 表现为植被生长旺盛期(7月)根际 土壤的净氮矿化能力显著高于植被生长初期(4月) $(p$ $<0.05)$ 。一方面因为不同取样季节平均温度和总降
水量的差异显著影响了土壤MBN含量(表1), 进而 对根际土壤净氮矿化造成间接影响(图3)。本研究区 4月份 0-20 cm 平均土壤温度为 $20.9{ }^{\circ} \mathrm{C}$, 总降水量为 $86.0 \mathrm{~mm} ; 7$ 月份平均土壤温度为 $28.6{ }^{\circ} \mathrm{C}$, 总降水量 为 $219.4 \mathrm{~mm}, 7$ 月平均土壤温度和总降水量明显高 于 4 月, 使得其根际土壤 MBN含量显著较高 $(p<$ 0.05)。Chen等(2017)研究也证明，降水量减少或增 加对土壤氮转化的影响是通过土壤微生物丰度和微 生物生物量来实现的。另一方面不同季节根际土壤 氮矿化差异与 $\mathrm{NH}_{4}^{+}-\mathrm{N}$ 和 $\mathrm{NO}_{3}^{-}-\mathrm{N}$ 含量有关(图3；表1)。 不同物种本身对铵态氮和硝态氮的吸收不同 (Moreau et al., 2019), 降水的淋溶作用会加剧根际 土壤养分有效性的差异, 改变根际土壤微生物群落, 从而对根际土壤氮转化造成差异性影响(Bell et al., 2015; Chen et al., 2017)。此外, 植物在生长旺盛期(7 月)需要更多的养分, 通过植物-微生物-土壤互作体 系加快土壤氮循环过程(Hishi et al., 2014), 因此7月 根际土壤 $N_{\text {min }} 、 N_{\text {amm }}$ 和 $N_{\text {nit }}$ 远高于 4 月。

\section{5 土壤化学性质和土壤微生物与根际土壤氮矿 化的关系}

在本研究中, 土壤化学性质对根际土壤氮矿化 变异的贡献率为 $29.2 \%$, 高于土壤微生物的贡献率 (图4)。全球氮矿化整合研究发现 $N_{\min }$ 主要受土壤理 化性质的影响, 可以解释 $N_{\min }$ 变异的 $30 \%$ (Liu et al., 2017), 而另一个基于全球和生物群落尺度的研究 发现 $N_{\min }$ 的变化主要归因于土壤微生物生物量( $\mathrm{Li}$ et al., 2019)。实际上, 生物地理学是由特殊的土壤化 学性质所驱动的(van der Wal et al., 2006)。在一定的 环境条件下, 植物和微生物形成一套稳定的相互作 用机制: 微生物利用植物分配到地下的光合产物 
(根系分泌物等)作为碳源和氮源, 将有机养分转化 成无机养分供植物吸收利用 (陆雅海和张福锁, 2006); 而植物根系分泌物及植物残体等释放到土 壤之后, 通过影响土壤碳氮含量等化学性质作用于 土壤微生物。因此, 微生物的特性很大程度上受土 壤化学性质的控制。有研究表明, 土壤理化性质可 以解释细菌群落变异的 79.6\% (Li et al., 2015)。另外, 仍存在近 $50 \%$ 的根际土壤氮矿化变异难以被解释, 一方面可能与本研究所选的指标有关, 另一方面室 内培养试验具有其相对适用性和局限性, 不能对野 外的自然环境进行全面的反映。在今后的研究中应 重点关注这些问题。

\section{4 结论}

较乔木来说, 林下灌草根际土壤氮矿化具有较 强的季节敏感性: 在马尾松和湿地松林内, 林下灌 草根际土壤 $N_{\mathrm{min}}$ 和 $N_{\mathrm{amm}}$ 在植被生长初期显著低于乔 木, 而在植被生长旺盛期显著提高, 与乔木不再具 有显著差异。 $\mathrm{NH}_{4}^{+}-\mathrm{N} 、 \mathrm{NO}_{3}^{-}-\mathrm{N} 、 \mathrm{TN}$ 及 $\mathrm{MBN}$ 含量极显 著影响了根际土壤氮矿化, 其中土壤化学性质对根 际土壤氮矿化变异的贡献率为 $29.2 \%$, 土壤微生物 为 $6.5 \%$ 。因此考虑不同林型及不同季节林下植被根 际土壤的氮矿化差异是准确评估人工林生态系统养 分循环状况的重要前提。

致谢 感谢中国科学院地理科学与资源研究所莫雪 丽、高雨秋和史丽娟在样本采集和数据分析工作中 给予的帮助。

\section{参考文献}

Aber JD, Nadelhoffer KJ, Steudler P, Melillo JM (1989). Nitrogen saturation in northern forest ecosystems. BioScience, 39, 378-386.

Bell CW, Asao S, Calderon F, Wolk B, Wallenstein MD (2015). Plant nitrogen uptake drives rhizosphere bacterial community assembly during plant growth. Soil Biology \& Biochemistry, 85, 170-182.

Blagodatskaya E, Blagodatsky S, Anderson TH, Kuzyakov Y (2014). Microbial growth and carbon use efficiency in the rhizosphere and root-free soil. PLOS ONE, 9, e93282. DOI: 10.1371/journal.pone.0093282.

Booth MS, Stark JM, Rastetter E (2005). Controls on nitrogen cycling in terrestrial ecosystems: a synthetic analysis of literature data. Ecological Monographs, 75, 139-157.

Borcard D, Gillet F, Legendre P (2011). Numerical Ecology with $R$. Springer, New York.
Burns RG, DeForest JL, Marxsen J, Sinsabaugh RL, Stromberger ME, Wallenstein MD, Weintraub MN, Zoppini A (2013). Soil enzymes in a changing environment: current knowledge and future directions. Soil Biology \& Biochemistry, 58, 216-234.

Chen FS, Zeng DH, He XY (2004). Soil nitrogen transformation and cycling in forest ecosystem. Chinese Journal of Ecology, 23(5), 126-133. [陈伏生, 曾德慧, 何兴元 (2004). 森林土壤氮素的转化与循环. 生态学杂志, 23(5), 126-133.]

Chen J, Xiao G, Kuzyakov Y, Jenerette GD, Ma Y, Liu W, Wang Z, Shen W (2017). Soil nitrogen transformation responses to seasonal precipitation changes are regulated by changes in functional microbial abundance in a subtropical forest. Biogeosciences, 14, 2513-2525.

Chen LY, Liu L, Qin SQ, Yang GB, Fang K, Zhu B, Kuzyakov Y, Chen PD, Xu YP, Yang YH (2019). Regulation of priming effect by soil organic matter stability over a broad geographic scale. Nature Communication, 10, 5112. DOI: 10.1038/s41467-019-13119-z.

Dai X, Fu X, Kou L, Wang H, Shock CC (2018). C, N, P stoichiometry of rhizosphere soils differed significantly among overstory trees and understory shrubs in plantations in subtropical China. Canadian Journal of Forest Research, 48, 1398-1405.

Finzi AC, Abramoff RZ, Spiller KS, Brzostek ER, Darby BA, Kramer MA, Phillips RP (2015). Rhizosphere processes are quantitatively important components of terrestrial carbon and nutrient cycles. Global Change Biology, 21, 2082-2094.

Fu XL, Wang JL, Di YB, Wang HM (2015a). Differences in fine-root biomass of trees and understory vegetation among stand types in subtropical forests. PLOS ONE, 10, e0128894. DOI: 10.1371/journal.pone.0128894.

Fu XL, Yang FT, Wang JL, Di YB, Dai XQ, Zhang XY, Wang HM (2015b). Understory vegetation leads to changes in soil acidity and in microbial communities 27 years after reforestation. Science of the Total Environment, 502, 280-286.

Gao YQ, Dai XQ, Wang JL, Fu XL, Kou L, Wang HM (2019). Characteristics of soil enzymes stoichiometry in rhizosphere of understory vegetation in subtropical forest plantations. Chinese Journal of Plant Ecology, 43, 258-272. [高雨秋, 戴晓琴, 王建雷, 付晓莉, 寇亮, 王 辉民 (2019). 亚热带人工林下植被根际土壤酶化学计 量特征. 植物生态学报, 43, 258-272.]

Gill RA, Jackson RB (2000). Global patterns of root turnover for terrestrial ecosystems. New Phytologist, 147, 13-31.

Gilliam FS, Yurish BM, Adams MB (2001). Temporal and spatial variation of nitrogen transformations in nitrogensaturated soils of a central Appalachian hardwood forest. Canadian Journal of Forest Research, 31, 1768-1785.

He JZ, Zhang LM (2013). Key processes and microbial 
mechanisms of soil nitrogen transformation. Microbiology China, 40, 98-108. [贺纪正, 张丽梅 (2013). 土壤氮素 转化的关键微生物过程及机制. 微生物学通报, 40 , 98-108.]

Hishi T, Urakawa R, Tashiro N, Maeda Y, Shibata H (2014). Seasonality of factors controlling $\mathrm{N}$ mineralization rates among slope positions and aspects in cool-temperate deciduous natural forests and larch plantations. Biology and Fertility of Soils, 50, 343-356.

Hodge A (2004). The plastic plant: root responses to heterogeneous supplies of nutrients. New Phytologist, 162, 9-24.

Jiang PP, Wang HM, Fu XL, Dai XQ, Kou L, Wang JL (2018). Elaborate differences between trees and understory plants in the deployment of fine roots. Plant and Soil, 431, 433-447.

Kuzyakov Y, Blagodatskaya E (2015). Microbial hotspots and hot moments in soil: concept \& review. Soil Biology \& Biochemistry, 83, 184-199.

Li CC, Li QR, Xu XL, Ouyang H (2016). Nitrogen acquisition strategies of Cunninghamia lanceolata at different ages. Acta Ecologica Sinica, 36, 2620-2625. [李常诚, 李倩茹, 徐兴良，欧阳华 (2016). 不同林龄杉木氮素的获取策 略. 生态学报, 36, 2620-2625.]

Li HX, Hu F, Liu MQ, Cai GX, Fan XH (2000). Mineralization and nitrification of nitrogen in red soil. Soils, 4, 194-197. [李辉信, 胡锋, 刘满强, 蔡贵信, 范晓晖 (2000). 红壤 氮素的矿化和硝化作用特征. 土壤, 4, 194-197.]

Li Y, Xu XH, Sun W, Shen Y, Ren TT, Huang JH, Wang CH (2019). Effects of different forms and levels of $\mathrm{N}$ additions on soil potential net $\mathrm{N}$ mineralization rate in meadow steppe, Nei Mongol, China. Chinese Journal of Plant Ecology, 43, 174-184. [李阳, 徐小惠, 孙伟, 申颜, 任婷 婷, 黄建辉, 王常慧 (2019). 不同形态和水平的氮添加 对内蒙古草甸草原土壤净氮矿化潜力的影响. 植物生 态学报, 43, 174-184.]

Li ZL, Tian DS, Wang BX, Wang JS, Wang S, Chen HYH, Xu XF, Wang CH, He NP, Niu SL (2019). Microbes drive global soil nitrogen mineralization and availability. Global Change Biology, 25, 1078-1088.

Li ZW, Xiao HB, Tang ZH, Huang JQ, Nie XD, Huang B, Ma WM, Lu YM, Zeng GM (2015). Microbial responses to erosion-induced soil physico-chemical property changes in the hilly red soil region of southern China. European Journal of Soil Biology, 71, 37-44.

Lin GG, Guo DL, Li L, Ma CG, Zeng DH (2018). Contrasting effects of ectomycorrhizal and arbuscular mycorrhizal tropical tree species on soil nitrogen cycling: the potential mechanisms and corresponding adaptive strategies. Oikos, 127, 518-530.

Liu Y, He NP, Wen XF, Yu GR, Gao Y, Jia YL (2016). Patterns and regulating mechanisms of soil nitrogen mineralization and temperature sensitivity in Chinese terrestrial ecosystems. Agriculture Ecosystems \& Environment, 215,
40-46.

Liu Y, Wang CH, He NP, Wen XF, Gao Y, Li SG, Niu SL, Butterbach-Bahl K, Luo YQ, Yu GR (2017). A global synthesis of the rate and temperature sensitivity of soil nitrogen mineralization: latitudinal patterns and mechanisms. Global Change Biology, 23, 455-464.

$\mathrm{Lu} \mathrm{YH,} \mathrm{Zhang} \mathrm{FS} \mathrm{(2006).} \mathrm{The} \mathrm{advances} \mathrm{in} \mathrm{rhizosphere} \mathrm{micro-}$ organisms. Soils, 38(2), 113-121. [陆雅海, 张福锁 (2006). 根际微生物研究进展. 土壤, 38(2), 113-121.]

Ma JM, Li K (2004). Current situation of research and prospects on forest ecosystem stability. World Forestry Research, 17(1), 15-19. [马姜明, 李昆 (2004). 森林生态 系统稳定性研究的现状与趋势. 世界林业研究, 17(1), 15-19.]

Mo XL, Dai XQ, Wang HM, Fu XL, Kou L (2018). Rhizosphere effects of overstory tree and understory shrub species in central subtropical plantations - A case study at Qianyanzhou, Taihe, Jiangxi, China. Chinese Journal of Plant Ecology, 42, 723-733. [莫雪丽, 戴晓琴, 王辉民, 付晓莉, 寇亮 (2018). 中亚热带典型人工林常见乔灌木 根际效应——江西泰和千烟洲为例. 植物生态学报, 42, 723-733.]

Moreau D, Bardgett RD, Finlay RD, Jones DL, Philippot L (2019). A plant perspective on nitrogen cycling in the rhizosphere. Functional Ecology, 33, 540-552.

Nilsson MC, Wardle DA (2005). Understory vegetation as a forest ecosystem driver: evidence from the northern Swedish boreal forest. Frontiers in Ecology and the Environment, 3, 421-428.

Parker SS, Schimel JP (2011). Soil nitrogen availability and transformations differ between the summer and the growing season in a California grassland. Applied Soil Ecology, 48, 185-192.

Phillips RP, Brzostek E, Midgley MG (2013). The mycorrhizalassociated nutrient economy: a new framework for predicting carbon-nutrient couplings in temperate forests. New Phytologist, 199, 41-51.

Phillips RP, Erlitz Y, Bier R, Bernhardt ES (2008). New approach for capturing soluble root exudates in forest soils. Functional Ecology, 22, 990-999.

Phillips RP, Fahey TJ (2006). Tree species and mycorrhizal associations influence the magnitude of rhizosphere effects. Ecology, 87, 1302-1313.

Ribbons RR, Levy-Booth DJ, Masse J, Grayston SJ, McDonald MA, Vesterdal L, Prescott CE (2016). Linking microbial communities, functional genes and nitrogen-cycling processes in forest floors under four tree species. Soil Biology \& Biochemistry, 103, 181-191.

Sha LQ, Meng Y, Feng ZL, Zheng Z, Cao M, Liu HM (2000). Nitrification and net $\mathrm{N}$ mineralization rate of soils under different tropical forests in Xishuangbanna, southwest China. Acta Phytoecologica Sinica, 24, 152-156. [沙丽清, 孟盈, 冯志立, 郑征, 曹敏, 刘宏茂 (2000). 西双版纳 
不同热带森林土壤氮矿化和硝化作用研究. 植物生态 学报, 24, 152-156.]

Sinsabaugh RL, Follstad Shah JJ (2012). Ecoenzymatic stoichiometry and ecological theory. Annual Review of Ecology, Evolution, and Systematics, 43, 313-343.

Spohn M, Carminati A, Kuzyakov Y (2013). Soil zymography-A novel in situ method for mapping distribution of enzyme activity in soil. Soil Biology \& Biochemistry, 58, 275-280.

Su LY, Cheng AX, Yu AL, Fu WQ, Zheng PY (1992). Investigation on mycorrhizae of forest trees in natural reserve of Mount Tianmu. Journal of Zhejiang Forestry College, 9(3), 263-276. [苏琍英, 程爱兴, 喻爱林, 傅卫庆, 郑平 谣 (1992). 天目山自然保护区林木菌根调查. 浙江林学 院学报, 9(3), 263-276.]

Subbarao GV, Wang HY, Ito O, Nakahara K, Berry WL (2007). $\mathrm{NH}_{4}^{+}$triggers the synthesis and release of biological nitrification inhibition compounds in Brachiaria humidicola roots. Plant and Soil, 290, 245-257.

Talbot JM, Allison SD, Treseder KK (2008). Decomposers in disguise: mycorrhizal fungi as regulators of soil $\mathrm{C}$ dynamics in ecosystems under global change. Functional Ecology, 22, 955-963.

Urakawa R, Ohte $\mathrm{N}$, Shibata $\mathrm{H}$, Isobe $\mathrm{K}$, Tateno R, Oda $\mathrm{T}$, Hishi T, Fukushima K, Inagaki Y, Hirai K, Oyanagi N, Nakata M, Toda H, Kenta T, Kuroiwa M, et al. (2016). Factors contributing to soil nitrogen mineralization and nitrification rates of forest soils in the Japanese archipelago. Forest Ecology and Management, 361, 382-396.

van der Wal A, van Veen JA, Smant W, Boschker HTS, Bloem J, Kardol P, van der Putten WH, de Boer W (2006). Fungal biomass development in a chronosequence of land abandonment. Soil Biology \& Biochemistry, 38, 51-60.

Vance ED, Brookes PC, Jenkinson DS (1987). Microbial biomass measurements in forest soils: the use of the chloroform fumigation-incubation method in strongly acid soils. Soil Biology \& Biochemistry, 19, 697-702.

Wang FM, Zou B, Li HF, Li ZA (2014). The effect of understory removal on microclimate and soil properties in two subtropical lumber plantations. Journal of Forest Research, 19, 238-243.

Wang GJ, Tian DL, Zhu F, Yan WD, Li SZ (2009). Net nitrogen mineralization in soils under four forest communities in Hunan Province. Acta Ecologica Sinica, 29, 1607-1615. [王光军, 田大伦, 朱凡, 间文德, 李树战 (2009). 湖南 省4种森林群落土壤氮的矿化作用. 生态学报, 29 , 1607-1615.]

Wang XZ, Hu ZL, Du YX, Liu YZ, Li LQ, Pan GX (2010). Comparison of microbial biomass and community structure of rhizosphere soil between forest and shrubbery in karst ecosystems. Soils, 42, 224-229. [王新洲, 胡忠良, 杜有新, 刘永卓, 李恋卿, 潘根兴 (2010). 喀斯特生态 系统中乔木和灌木林根际土壤微生物生物量及其多样
性的比较. 土壤, 42, 224-229.]

Wu LK, Lin XM, Lin WX (2014). Advances and perspective in research on plant-soil-microbe interactions mediated by root exudates. Chinese Journal of Plant Ecology, 38, 298-310. [吴林坤，林向民，林文雄 (2014). 根系分泌 物介导下植物-土壤-微生物互作关系研究进展与展望. 植物生态学报, 38, 298-310.]

Xiao HY, Liu B, Yu ZP, Wan XH, Sang CP, Zhou FW, Huang ZQ (2017). Seasonal dynamics of soil mineral nitrogen pools and nitrogen mineralization rate in different forests in subtropical China. Chinese Journal of Applied Ecology, 28，730-738. [肖好燕，刘宝，余再鹏，万晓华，桑昌鹏， 周富伟，黄志群 (2017). 亚热带不同林分土壤矿质氮库 及氮矿化速率的季节动态. 应用生态学报, 28, 730-738.]

Yin HJ, Xu ZF, Chen Z, Wei YY, Liu Q (2012). Nitrogen transformation in the rhizospheres of two subalpine coniferous species under experimental warming. Applied Soil Ecology, 59, 60-67.

York LM, Carminati A, Mooney SJ, Ritz K, Bennett MJ (2016). The holistic rhizosphere: integrating zones, processes, and semantics in the soil influenced by roots. Journal of Experimental Botany, 67, 3629-3643.

Zhang JB, Cai ZC, Zhu TB, Yang WY, Müller C (2013a). Mechanisms for the retention of inorganic $\mathrm{N}$ in acidic forest soils of southern China. Scientific Reports, 3, 2342. DOI: $10.1038 /$ srep02342.

Zhang JB, Zhu TB, Cai ZC, Muller C (2011). Nitrogen cycling in forest soils across climate gradients in Eastern China. Plant and Soil, 342, 419-432.

Zhang YC, Zhang JB, Meng TZ, Zhu TB, Muller C, Cai ZC (2013b). Heterotrophic nitrification is the predominant $\mathrm{NO}_{3}^{-}$production pathway in acid coniferous forest soil in subtropical China. Biology and Fertility of Soils, 49, 955-957.

Zhao Q, Zeng DH, Fan ZP (2010). Nitrogen and phosphorus transformations in the rhizospheres of three tree species in a nutrient-poor sandy soil. Applied Soil Ecology, 46, 341-346.

Zhao QG (1995). Degradation of red soil in China. Soils, 38, 281-285. [赵其国 (1995). 我国红壤的退化问题. 土壤, 38, 281-285.]

Zhu B, Gutknecht JLM, Herman DJ, Keck DC, Firestone MK, Cheng W (2014). Rhizosphere priming effects on soil carbon and nitrogen mineralization. Soil Biology \& Biochemistry, 76, 183-192.

Zulkarnaen N, Cheng Y, Zhang JB (2019). Effects of land use on soil nitrogen mineralization and nitrification transformation in red soil in subtropical region of China. Chinese Journal of Soil Science, 50, 1210-1217. [Zulkarnaen N, 程谊, 张金波 (2019). 土地利用方式对红壤氮素矿化和 硝化作用的影响. 土壤通报, 50, 1210-1217.]

责任编委: 王根轩 编辑: 赵 航 